\title{
INTRODUCTION TO INDUSTRIAL MATHEMATICS
}

\author{
Anjali Singh ${ }^{1}$, Deepanshi Vij ${ }^{2}$, Dr. Manimala ${ }^{3}$, Ms. Sherry Verma ${ }^{4}$ \\ E-Mail Id: ${ }^{1}$ anjalisingh.btech18@ansaluniversity.edu.in, ${ }^{2}$ deepanshivij.btech18@ansaluniversity.edu.in , \\ ${ }^{3}$ manimala@ansaluniversity.edu.in, ${ }^{4}$ sherryverma@ansaluniversity.edu.in \\ School of Engineering and Technology, Ansal University, Gurugram, Haryana, India
}

\begin{abstract}
There is no question that mathematics has played a leading role in the development of physics and engineering through the last century. However the direct participation of mathematicians in solving the problems of industry is the new trend, so called "industrial mathematics". Industrial mathematics has developed as a new profession. In this report, we will talk about the concepts of industrial mathematics and its importance in the society. Keywords: industrial mathematics.
\end{abstract}

\section{INTRODUCTION}

Mathematics is one of the oldest and fundamental sciences. The word 'mathematics' has been derived from the Greek word mathema meaning 'knowledge, study, learning'. It has no generally accepted definition but deals with logical reasoning and quantitative calculation.[3]

Mathematician is a person who uses the exclusive knowledge of mathematics in their work. The education of mathematicians focuses on mathematics itself as a way to understand the relationship between abstract objects. Some mathematicians explore theories while others apply them to solve daily problems. They try to be as precise and concise as they could while solving a problem. When asked to solve a problem, usually a person will think of the ways they know that can be applied to solve the problem and would back-off if he is unable to find such a way. But a mathematician will abstract the problem into a mathematical problem and apply mathematical abilities to solve it. If he is unsuccessful in solving the problem, he re-thinks of the models and takes a different approach.He continues until he is successful in finding the solution.[1]

Modern mathematics is broadly divided into Pure Mathematics and Applied Mathematics. The difference between the two is based on their application. [4] Pure Mathematics is a branch of mathematics that is studied, and principles are developed for the sake of mathematics rather than their immediate use. In other words, it is based on number theory. The Fibonacci Series is an example of this, which has almost no significant use to mankind. On the contrary, Applied Mathematics is a branch of mathematics that is involved in the study of the physical or biological world, that is, studied purely for application purposes. It is based on numerical methods, having extensive use in Computer science and engineering.

\section{INDUSTRIAL MATHEMATICS}

Mathematics is the most versatile of all the sciences. It is uniquely well placed to respond to the demands of a rapidly changing economic landscape.Unfortunately, academic mathematics is insufficiently connected to mathematics used in the industries, making it difficult to build closer connections to industry. Hence, academic mathematical science must strike a better balance between theory and application.

Industrial Mathematics is a new research field in mathematics, which deals with the use of mathematical modelling to solve industrial problems, thereby serving as the foundation for developing future technologies.It comprises of a mixture of pure and applied mathematical modelling such as Partial Differential Equations, Probability, Statistics, Discrete Mathematics and many more. In other words, it will integrate and reorganize pure and applied mathematics into a volatile form so as to respond to the needs of industrial technologies.

Let us consider a case study of a Mexican company who had complained regarding the noise from the car-seat air-con fan blowers. They were having a great loss as their products were returned stating about an undesirable noise. They did not clearly understand what kind of noise was undesirable.Many analysis were made but the noise considered undesirable by the Mexican manufacturing plant was different to what the client plant considered to be.This is where mathematicians rescued them. They measured the noise frequency spectrum with a special microphone and computer, investigated which frequencies were annoying to human hearing, statistically analysed the noise spectrum and revealed which frequency bands were undesirable from the viewpoint of the client company. They then wrote a computer script that could automatically determine if an item is defective or not.[1] This was one of the incidents when industry benefited from the work of mathematicians.

It is evident from the above case study that the ability to effectively use mathematical modelling, simulation, control and optimisation will be the foundation for technological and economic development, helping in achieving better understanding of industrial models and processes. 
ICACCG2020 30-31 July, 2020, Ansal University, Gurgaon, India

International Journal of Technical Research \& Science (Special Issue)

ISSN No.:2454-2024 (online)

\section{THE IDEA OF "CONSTRUCTION AND ANALYSIS MODEL" AND INDUSTRIAL MATHEMATICS}

The use of the concepts and methods of mathematics as an aid to understanding real world problems arising from diverse fields in the physical, life and social sciences is now a well established approach to gain frontier knowledge in these areas. We believe that one of the most important contributions that mathematics makes in the study of such complex situations and problems is through the novel idea of "construction and analysis of models", a more holistic approach as compared to the mere custom-made "black box" modelling methodology of prevalent industrial R\&D.

Any model can be defined as a simplified representation of certain aspects of a real world system or problem. A mathematical model is a model created in the abstract world using mathematical concepts, and manipulation of the model via mathematical theories and techniques or computer-aided numerical computation would provide the necessary mathematical solutions. These solutions are then physically interpreted and strenuously validated. The real world is re-entered by translating these theoretical solutions into practical solutions to the original real problem, and later put to further applications in the form of useful predictions. Alternatively, we could propound a statistical model instead, after gathering much data from the real life problem. The corresponding cycle of idea then follows suit. The same applies to any man-made real engineering and industrial problems; any model can be defined as a simplified representation of certain aspects of these real man-made systems.

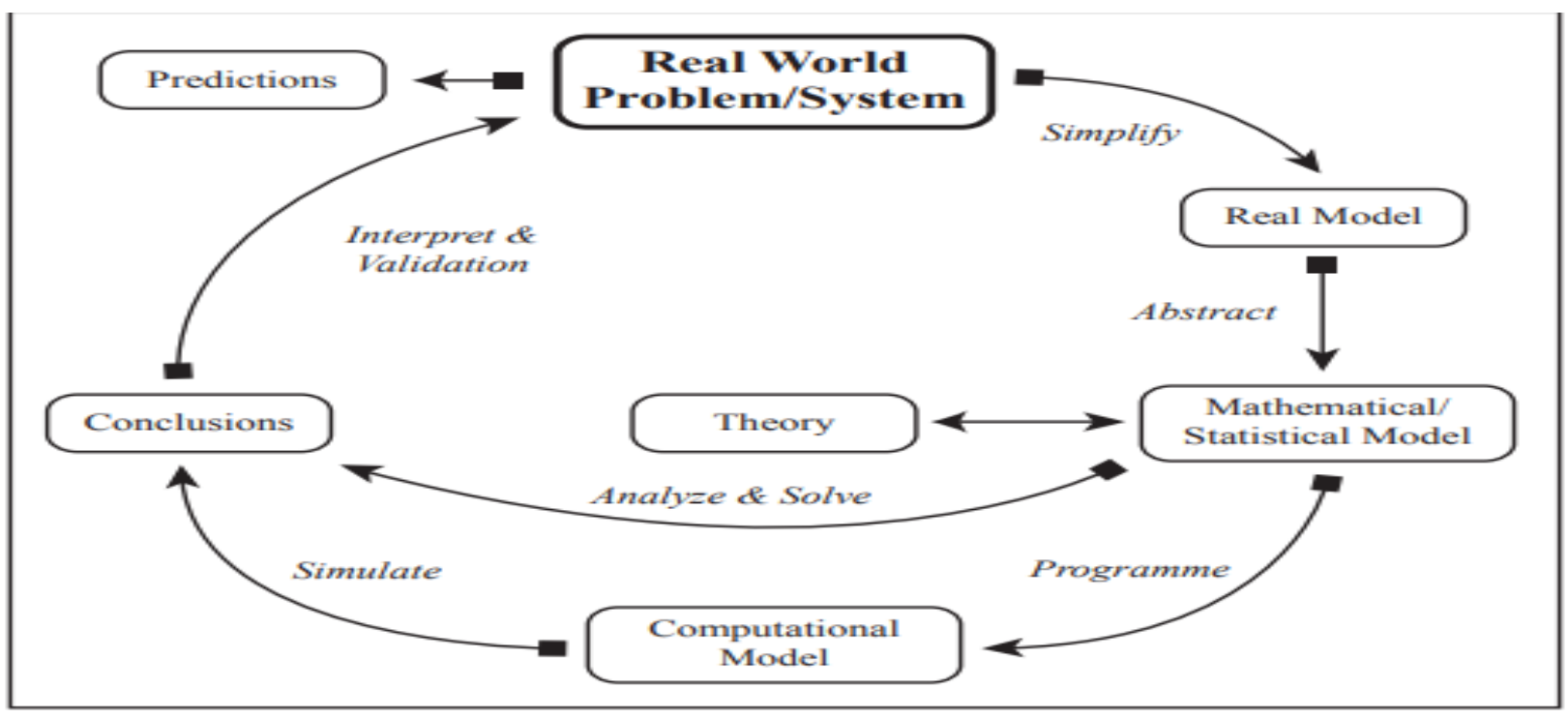

Fig. 3.1 Construction and Analysis Model

To increase the awareness of and appreciation for the effectiveness of the applications of mathematics, statistics, and computational procedures to solving real industrial problems of a "non-textbook" nature, the field of industrial mathematics is introduced. The word "industrial" is used to include corporations, businesses, firms, and government agencies. As we have stated earlier, the notable nature of this brand of mathematics can be brought to fore through the cycle of the approach of "construction and analysis of models", as entrenched in figure. Many are of the opinion that this trademark of industrial mathematics would stimulate greater awareness in the wider community of the power of mathematics in providing solution paths to real-world problems.[5]

\section{MEANS OF INTERACTION BETWEEN MATHEMATICS AND INDUSTRY}

Problems in industry which benefit significantly from mathematics are seen on different scales:

$>$ Specific problems where the current methods or commercial codes fail, where a new feature has to be included, where current models do not meet the requirement.

$>$ Medium scale problems where the transfer of a new technology, algorithmic approach or such has to be performed or where a new mathematical software product has to be brought into the market. This is very often done via companies that are spun out of a research lab or an academic institution. These mathematical spin-offs show a high survival rate in the market or are bought out by global players thus creating novel high-tech jobs with high salaries. These kinds of projects typically require 3-6 person years. 
ICACCG2020 30-31 July, 2020, Ansal University, Gurgaon, India

International Journal of Technical Research \& Science (Special Issue)

ISSN No.:2454-2024 (online)

$>$ Large-scale multi-physics, multi-scale, multi-mathematics are problems where different physical models are coupled, where different areas of mathematics are used and where there are essentially no methods available. Such projects can have an order of 20-30 person years.[6]

\section{MATHEMATICAL AREAS AND INDUSTRIAL APPLICATIONS}

Industrial mathematics has not only been useful for solving the industrial problems in a better way. But it has also been used to check designs before manufacture, to test plants before construction and to explain the occurrence of faults in processes, if any, helping the companies to have calculated risks. The following table gives a view of the association between the areas of mathematics and applications:

Table-5.1 Mathematical Areas

\begin{tabular}{|l|l|}
\hline Mathematical Areas & Application Areas \\
\hline Algebra and number theory & Cryptography \\
\hline Computational fluid dynamics & Aircraft and automobile design \\
\hline Differential equations & Aerodynamics, porous media, finance \\
\hline Discrete mathematics & Communication and information security \\
\hline Formal system and logic & Computer security, verification \\
\hline Geometry & Computer-aided engineering and design \\
\hline Nonlinear control & Operation of mechanical and electrical system \\
\hline Numerical analysis & Essentially all applications \\
\hline Optimization & Asset allocation, shape and system design \\
\hline Stochastic processes & Signal analysis \\
\hline Parallel algorithms & Weather modeling and prediction, crash simulation \\
\hline Statistics & Design of experiments, analysis of large data sets \\
\hline
\end{tabular}

Industrial Mathematics is an interdisciplinary field. In other words, it not only focuses on mathematics but also on other fields such as business, computer science, engineering etc. Since mathematics is the foundation of many other subjects, a number of workers using mathematical techniques (eg:engineers, computer scientists, economists, etc) is greater than the number of formally designated mathematicians (eg:staticians, research analysts, etc).In other words, applied mathematician collaborate with other workers to achieve common solution to problems.[2]

\section{CONCLUSION}

With the rapid development of science and technology, modern manufacturing and service industries have changed drastically. Industrial Mathematics is the main factor in realising and implementing sophisticated methods (large databases, inexpensive computing, etc) to meet the new demand.Also, Industrial mathematicians collaborate with workers from different fields to produce innovative products, as flow of ideas runs strongly in both directions. But building and maintaining work relationships between both industry and academics is not emphasised. So, nonacademic mathematicians should be encouraged to enhance research, teaching and application throughout mathematics, science, industry and engineering, to not only increase the range of real-world problems but also enhance the positive impact on society.[2]

\section{REFERENCES}

[1] The importance of math for industry through some examples

[2] AKOOS-PNU International Conference 2014, Pusan, South Korea, Pusan National University

[3] Industrial Mathematics: Concepts, Algorithms and Complexity

[4] Department of Mathematics, Pulchowk University, Institute of Engineering, Tribhuvan University

[5] Images of Mathematics Held by University Teachers of Mathematical Sciences

[6] Educational Studies in Mathematics

[7] Pure, Applied or just Mathematics?

[8] Andrew J. Woldar, Villanova University

[9] An Overview of the Importance of Industrial Mathematics

[10] Kepentingan Matematik Industri: Satu Gambaran Keseluruhan

[11] Mathematics and its relationship with industry

DOI Number: https://doi.org/10.30780/specialissue-ICACCG2020/010 